\title{
LEAKAGE ANALYSIS OF THE EVOLVE FIRST WALL*
}

\author{
by \\ Saurin Majumdar \\ Fusion Power Program \\ Argonne National Laboratory \\ Argonne, IL 60439 USA
}

Phone: 630-252-5136 Fax: 630-252-4798 Email: majumdar@anl.gov

The submitted manuscript has been created by the
University of Chicago as Operator of Argonne National
Laboratory ("Argonne") under Contract No. W-31-109-
ENG-38 with the U.S. Department of Energy. The U.S.
Government retains for itself, and others acting on its
behalf, a paid-up, nonexclusive, irrevocable worldwide
license in said article to reproduce, prepare derivative
works, distribute copies to the public, and perform
publicly and display publicly, by or on behalf of the
Government.

Government.

January, 2002

Manuscript submitted for presentation at the 6th International Symposium on Fusion Nuclear Technology, April 07-12, 2002, San Diego. 
* Work supported by Office of Fusion Energy, U.S. Department of Energy, under Contract No W-31-109-Eng-38. 


\title{
LEAKAGE ANALYSIS OF THE EVOLVE FIRST WALL*
}

\author{
Saurin Majumdar \\ Fusion Power Program, Argonne National Laboratory, Argonne, IL 60439 \\ Phone: 630-252-5136 Fax: 630-252-4798 Email: majumdar@anl.gov
}

\begin{abstract}
Leakage of lithium through cracks in the first wall of EVOLVE was analyzed for two limiting cases, which are simplified versions of the real case, where the lithium enters the cracks as liquid and flashes to vapor phase within the first wall. Leakage rates were calculated for the cases of liquid lithium flow and lithium vapor flow. Inasmuch as the coolant pressure is close to the saturation pressure, the limiting case of lithium vapor flow should be closer to reality. The impact of lithium leakage on first-wall cooling and plasma contamination is discussed.
\end{abstract}

\section{Introduction}

The first wall of Evaporation of Lithium and Vapor Extraction (EVOLVE) concepts [1] will be cooled by the evaporation of lithium whose temperature will be in the range 1200 and $1400^{\circ} \mathrm{C}$, corresponding to saturation pressures of 0.035 and $0.15 \mathrm{MPa}$, respectively. In the toroidal flow concept, these pressures will create very low primary stresses in tungsten first wall tubes of 6-cm diameter and 3-mm wall thickness. However, cyclic surface heat flux will create cyclic thermal stresses, which may lead to initiation and propagation of fatigue cracks through the first wall. The present paper addresses the problem of the leakage rate of lithium through a fatigue crack in the first wall. The impact of the lithium leakage rate on cooling of the first wall and plasma contamination is discussed. The impact of lithium leakage on reactor performance was analyzed earlier by Jones et al. [2] in connection with UWMAK-II and NUWMAK design studies. However, the temperature of lithium in these designs was much lower than in EVOLVE.

\section{Leakage Analysis}

Since the pressure of the lithium vapor in the EVOLVE first wall tube is quite low $(0.035-$ $0.15 \mathrm{MPa}$ ), surface tension effects may play an important role in determining if leakage of liquid lithium will occur through a tight fatigue crack in the first wall into the plasma chamber. Capillary effects may even prevent leakage of liquid lithium through a tight fatigue crack if lithium does not wet the crack flanks. However, currently, the consensus is that liquid lithium does wet tungsten at these temperatures. Consequently, there will be no beneficial capillary

\footnotetext{
* Work supported by Office of Fusion Energy, U.S. Department of Energy, under Contract No W-31-109-Eng-38.
} 
effect and liquid lithium may, in fact, ooze out into the plasma chamber by capillary pumping even in the absence of a pressure difference across the first wall (Fig. 1).

Since the inlet pressure is close to saturation vapor pressure of lithium, as the liquid lithium enters the crack, viscous pressure drop will cause the liquid to flash to vapor (Fig. 2). The heat of vaporization will be supplied by the surface heat flux as well as the surrounding liquid (in fact, flashing will occur even without a surface heat flux). The local velocity of the vapor immediately after flashing will be high, but it will be quickly damped by high viscous dissipation owing to the tight and meandering nature of fatigue cracks. Also, because of the large flow path length to width ratio $(\mathrm{L} / \delta)$ of fatigue cracks, equilibrium will be restored within some multiples of the crack width close to the entrance. In this paper, the complex non-equilibrium phenomena related to flashing of liquid lithium to vapor phase inside the fatigue crack and subsequent viscous dissipation including possible two-phase flow are not considered. Instead, two limiting cases are analyzed. First, the leakage rate is estimated by assuming that lithium leakage occurs as a liquid, which flashes to vapor into the plasma chamber at the crack exit plane. In the second case, the lithium vapor leakage rate is estimated by assuming that lithium enters the fatigue crack as a single phase vapor. This is equivalent to assuming that the pressure drop within the nonequilibrium transition zone inside the fatigue crack is small compared to the overall pressure drop and the mass flow rate of lithium vapor is determined by equilibrium of pressure and viscous forces. Of the two limiting cases, the second case should be closer to reality.

\subsection{Liquid Lithium Leakage Analysis}

It is assumed that the Reynold's number of the flow is negligibly small so that inertia effects can be neglected in comparison to viscous effects, and pressure drops due to entrance and flow bends can be ignored. In such cases, the following pressure conditions apply

$$
\mathrm{p}_{\text {exit }}=\mathrm{p}_{\mathrm{o}}+\Delta \mathrm{p}_{\mathrm{c}}-\Delta \mathrm{p}_{\mathrm{f}}-\Delta \mathrm{p}_{\mathrm{MHD}}=0
$$

where

$p_{\text {exit }}=$ the pressure at the crack exit plane,

$\mathrm{p}_{\mathrm{o}}=$ pressure at the crack entrance plane,

$$
\Delta \mathrm{p}_{\mathrm{c}}=\frac{2 \sigma}{\delta}=\text { capillary pressure head }
$$

$\sigma=$ surface tension of liquid lithium, $\delta=$ crack opening displacement

$\Delta \mathrm{p}_{\mathrm{f}}=$ pressure drop due to viscous effect, and

$\Delta \mathrm{p}_{\mathrm{MHD}}=$ pressure drop due to magnetohydrodynamic (MHD) effects . 
The pressure drop due to incompressible viscous effects (Poiseuille flow) is related to the fully developed flow velocity by (in the absence of magnetic field)

$$
\Delta \mathrm{p}_{\mathrm{f}}=\frac{32 \mu \mathrm{L}}{\mathrm{D}^{2}} \mathrm{v}
$$

where

$\mu=$ coefficient of viscosity, $L=$ flow path length (can be approximated by tube wall thickness $), \mathrm{v}=$ flow velocity, and $\mathrm{D}=$ crack hydraulic diameter $(\approx 2 \delta)$.

For MHD pressure drop, we use a correlation developed by L. Bühler ${ }^{1}$ for fully developed flows with large Hartmann number (i.e., viscous forces negligible compared to magnetic forces).

$$
\Delta \mathrm{p}_{\mathrm{MHD}}=\sigma_{\mathrm{liq}} \mathrm{B}^{2} \mathrm{LKv}
$$

where $\sigma_{\text {liq }}=$ electrical conductivity of liquid (A/V-m), B = magnetic field (Tesla), and $\mathrm{K}$ is given by

$$
\begin{aligned}
& K=\frac{1}{1+\frac{\alpha}{\beta}} \\
& \beta=\sigma_{\text {wall }} / \sigma_{\text {liq }} \\
& \alpha \approx 1 \text { for circular tubes and thin gaps, and } \\
& \sigma_{\text {wall }}=\text { electrical conductivity of tube wall. }
\end{aligned}
$$

Combining Eqs. 1, 2, 3, and 4a, and solving for v,

$$
\mathrm{v}=\frac{\mathrm{p}_{\mathrm{o}}+\Delta \mathrm{p}_{\mathrm{c}}}{\sigma_{\mathrm{liq}} \mathrm{B}^{2} \mathrm{LK}+\frac{32 \mu \mathrm{L}}{\mathrm{D}^{2}}}
$$

A critical parameter for calculating leakage rates is the crack opening area (A), which is the pressure-dependent opened area of the crack. The crack opening area of an axial throughwall crack in a thin-walled tube was calculated by the Zahoor equation [3]. The mass flow rate is given by

${ }^{1}$ L. Bühler,"MHD Flows in Thick-walled Ducts", Technical Report FZKA 6066, Forschungszentrum Karlsruhe (1998). 


$$
\frac{\mathrm{dm}}{\mathrm{dt}}=\rho_{\text {liq }} \mathrm{Av}
$$

where $\rho_{\text {liq }}=$ mass density of liquid lithium.

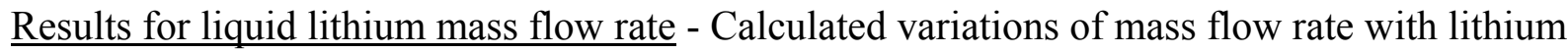
vapor pressure in the first wall tube are shown for initial crack openings of 1 and $10 \mu \mathrm{m}$ in Figs. $3 \mathrm{a}$ and $3 \mathrm{~b}$, respectively. As expected, capillary effects are important at low pressures that are of interest to EVOLVE (0.015 to $0.15 \mathrm{MPa})$ and at lower initial crack openings. On the other hand, MHD effects are negligible for a planar crack of small opening. Whether the same conclusion holds for an irregular-shaped fatigue crack remains open. For larger crack openings, MHD pressure drops are important. The maximum leak rates for a $25 \mathrm{~mm}$ long crack at $0.15 \mathrm{MPa}$ are 3 $\mathrm{x} 10^{-3}$ and $0.15 \mathrm{gm} / \mathrm{s}$ for initial crack opening of 1 and $10 \mu \mathrm{m}$, respectively. These values should be taken as upper bounds to the mass flow rate because evaporation of lithium within the fatigue crack (possibly close to the inlet) will probably reduce the mass flow rate significantly.

To check whether the assumptions that Hartmann number is large and Reynold's number is low are satisfied, they are plotted against lithium pressure in Figs 4a-b. Note that in the pressure regime of interest to EVOLVE, the Hartmann number is $>1$ for initial crack opening of $1 \mu \mathrm{m}$ and $>12$ for initial crack opening of $10 \mu \mathrm{m}$. Thus the assumption of large Hartmann number is increasingly violated with decreasing initial crack opening. Although the Reynold's number is $>10$ at an initial crack opening of $10 \mu \mathrm{m}$, the interaction parameter (ratio between magnetic forces and inertial forces) is also $\geq 10$ for pressures $\leq 0.05 \mathrm{MPa}$, indicating that magnetic forces dominate inertia forces. It is evident that the assumption of low Reynold's number is increasingly violated at higher pressures and larger initial crack opening, and consequently inertia forces cannot be ignored.

\subsection{Lithium Vapor Leakage Analysis}

The description of gas flow in vacuum systems is generally separated into three regimes, depending on the values of a nondimensional parameter called the Knudsen number defined as the ratio between the mean free path $(\mathrm{L})$ of a molecule and the characteristic dimension of the flow channel [4]. For our case, the characteristic channel dimension is the crack opening displacement $\delta$. In the high pressure range, where the mean free path of a gas molecule is small compared to $\delta$ (Knudsen number $<0.01$ ), collision between molecules occur more frequently than collision between molecules and the channel wall. Conventional flow in this range is called viscous flow, which can be analyzed by theory of hydrodynamics. At low pressures, the mean free path is large compared to $\delta$ and the gas flow is limited by molecular collision with the wall of the flow channel. Flow at large Knudsen numbers (Knudsen number $>1$ ) is called molecular flow. Transition from viscous to molecular flow occurs at intermediate values of Knudsen number $(0.01<$ Knudsen number $<1)$ where both types of collision are important. The mean free path length $(\mathrm{L}$ in $\mathrm{m})$ of any gas molecule is related to its temperature $(\mathrm{T}$ in $\mathrm{K})$, molecular weight (M gram), pressure ( $\mathrm{p}$ in $\mathrm{MPa}$ ) and viscosity ( $\mu$ in Pa-s) by the following equation [4] 


$$
\mathrm{L}=1.1451 \times 10^{-2} \frac{\mu}{\mathrm{p}}\left(\frac{\mathrm{T}}{\mathrm{M}}\right)^{1 / 2}
$$

Since the mean free path of air at $25^{\circ} \mathrm{C}$ is related to pressure, the flow regimes for air at $25^{\circ} \mathrm{C}$ can be expressed as follows [4]:

Viscous flow occurs when $\mathrm{p} \delta>6.79 \times 10^{-7}$

molecular flow occurs when $\mathrm{p} \delta<6.79 \times 10^{-9}$, and

transition flow occurs when $6.79 \times 10^{-9}<\mathrm{p} \delta<6.79 \times 10^{-7}$,

where $\mathrm{p}$ is in $\mathrm{MPa}$ and $\delta$ is in $\mathrm{m}$. The above criterion was used by Jones et al. [4] for analyzing leakage rate of lithium vapor into the plasma chamber. However, if we use the properties of lithium vapor at $1200^{\circ} \mathrm{C}$, the flow regimes can be expressed as follows:

Viscous flow occurs when $\mathrm{p} \delta>2.5 \times 10^{-6}$,

molecular flow occurs when $\mathrm{p} \delta<2.5 \times 10^{-8}$, and

transition flow occurs when $2.5 \times 10^{-8}<\mathrm{p} \delta<2.5 \times 10^{-6}$,

Since the temperature of lithium in the Jones et al. [2] study was $500^{\circ} \mathrm{C}\left(\mathrm{p} \delta=4 \times 10^{-12} \mathrm{MPa}-\mathrm{m}\right)$, the lithium vapor flow was primarily molecular. In the case of EVOLVE, $\mathrm{p} \delta=3.5 \times 10^{-7}$ at $1200^{\circ} \mathrm{C}, 7.8 \times 10^{-7}$ at $1300^{\circ} \mathrm{C}$, and $1.6 \times 10^{-6} \mathrm{MPa}-\mathrm{m}$ at $1400^{\circ} \mathrm{C}$. Consequently, the flow is likely to be in the transition range at the temperatures of interest to EVOLVE. Since there is no reliable model for predicting gas leakage rate in the transition regime, the lithium vapor leakage rate was calculated by both the incompressible viscous flow theory and the molecular flow theory.

Calculation of leakage rate for gas is more complicated than that for liquid because the density of gas is a strong function of pressure. A flow rate $\mathrm{Q}_{\mathrm{g}}$ can be defined relating it to the volumetric flow rate and the pressure $(p)$ at which it is measured as follows [4]:

$$
Q_{g}=p \frac{d V}{d t}
$$

Note that the unit for $\mathrm{Q}_{\mathrm{g}}$ is $\mathrm{MPa}-\mathrm{m}^{3} / \mathrm{s}$. The ideal gas law can be used to show that

$$
\mathrm{Q}_{\mathrm{g}}=\mathrm{p} \frac{\mathrm{dV}}{\mathrm{dt}}=\mathrm{kT} \frac{\mathrm{dN}}{\mathrm{dt}}
$$

where $\mathrm{T}$ is absolute temperature, $\mathrm{N}$ is the number of molecules of gas, and $\mathrm{k}$ is Boltzmann constant. The molar leakage rate can be calculated by Eq. $8 \mathrm{~b}$ from a knowledge of $\mathrm{Q}_{\mathrm{g}}$. We 
assume that the gas flow occurs under isothermal condition. The flow rate $\mathrm{Q}_{\mathrm{g}}$ for fully developed incompressible viscous (Poiseuille) flow is then given by [4]

$$
\mathrm{Q}_{\mathrm{g}}=\frac{\mathrm{AD}^{2} \Delta \mathrm{p}}{32 \mu \mathrm{L}} \frac{\mathrm{p}_{\mathrm{o}}+\mathrm{p}_{\text {exit }}}{2} \approx \frac{\mathrm{AD}^{2} \mathrm{p}_{\mathrm{o}}^{2}}{64 \times 10^{-6} \mu \mathrm{L}} \text { in } \mathrm{MPa}-\mathrm{m}^{3} / \mathrm{s}
$$

where the lengths are in $\mathrm{m}, \mathrm{p}_{\mathrm{o}}$ is the inlet pressure (MPa) and $\mathrm{p}_{\text {exit }}$ is the exit pressure (MPa) taken as $\approx 0$, and $\Delta \mathrm{p}(\mathrm{MPa})$ is the pressure drop through the first wall and $\mu$ is in Pa-s. The other symbols are defined after Eq. 3 .

For pure molecular flow, the molecules have a Maxwellian distribution of velocity and the arithmetic mean flow velocity is given by [4]

$$
\mathrm{v}_{\mathrm{m}}=\left(\frac{8 \mathrm{RT}}{\pi \mathrm{M}}\right)^{1 / 2}=145.51\left(\frac{\mathrm{T}}{\mathrm{M}}\right)^{1 / 2} \text { in } \mathrm{m} / \mathrm{s}
$$

where $\mathrm{R}=\mathrm{N}_{\mathrm{A}} \mathrm{k}$ is the molar universal gas constant, $\mathrm{N}_{\mathrm{A}}$ is Avogadro's number, $\mathrm{M}$ is molecular weight $(\mathrm{g} / \mathrm{mole})$. The molecular flow rate $\mathrm{Q}_{\mathrm{g}}$ through an elliptically opened crack of length $2 \mathrm{c}$ (in $\mathrm{m}$ ) is given by [4]

$$
\mathrm{Q}_{\mathrm{g}}=\frac{2 \sqrt{2}}{3 \pi \mathrm{L}} \frac{\mathrm{A}^{2}}{\left[\mathrm{c}^{2}+\left(\frac{\delta}{2}\right)^{2}\right]^{1 / 2}} \mathrm{v}_{\mathrm{m}}\left(\mathrm{p}_{\mathrm{o}}-\mathrm{p}_{\text {exit }}\right) \approx \frac{43.67 \mathrm{p}_{\mathrm{o}} \mathrm{A}^{2}}{\mathrm{Lc}}\left(\frac{\mathrm{T}}{\mathrm{M}}\right)^{1 / 2} \text { in MPa-m } \mathrm{m}^{3 / \mathrm{s}}
$$

Mass flow rate (in $\mathrm{g} / \mathrm{s}$ ) corresponding to $\mathrm{Q}_{\mathrm{g}}$ is given by

$$
\frac{\mathrm{dm}}{\mathrm{dt}}=120272 \frac{\mathrm{Q}_{\mathrm{g}} \mathrm{M}}{\mathrm{T}}
$$

where $\mathrm{Q}_{\mathrm{g}}$ is in $\mathrm{MPa}-\mathrm{m}^{3} / \mathrm{s}, \mathrm{M}$ is in $\mathrm{g} / \mathrm{mole}$, and $\mathrm{T}$ is in $\mathrm{K}$.

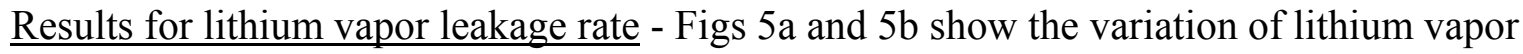
leakage rate through a $25 \mathrm{~mm}$ long crack with temperature under saturation pressure by molecular flow and by viscous flow for initial crack opening of 10 and $1 \mu \mathrm{m}$, respectively. Note that molecular flow controls the mass flow rate for small crack opening and viscous flow controls the mass flow rate for large crack opening and high temperature (i.e., high pressure). At a lithium temperature of $1400^{\circ} \mathrm{C}$ (saturation pressure $=0.15 \mathrm{MPa}$ ) and for initial crack width of $10 \mu \mathrm{m}$, the mass flow rate is $5 \times 10^{-4} \mathrm{~g} / \mathrm{s}$. The mass flow rate is lower for smaller initial crack opening. Calculated variation of lithium vapor velocity with lithium temperature is plotted in Fig 6 a for various values of initial crack opening. Note that the maximum vapor velocity at $1400{ }^{\circ} \mathrm{C}$ ( saturation pressure $=0.15 \mathrm{MPa}$ ) is $40 \mathrm{~m} / \mathrm{s}$ for a crack that is initially open by $10 \mu \mathrm{m}$. Thus, the 
assumption of incompressibility is justified up to an initial crack width of $10 \mu \mathrm{m}$.

Compressibility and inertia effects may become important if initial crack width is significantly greater than $10 \mu \mathrm{m}$. For a first wall area $=500 \mathrm{~m}^{2}$, a mass flow rate of $5 \times 10^{-4} \mathrm{~g} / \mathrm{s}$ distributed uniformly on the first wall corresponds to $10^{17} \mathrm{Li}$ atoms $/ \mathrm{m}^{2} / \mathrm{s}$ per crack. Fig. $6 \mathrm{~b}$ shows the variation of the mean molecular flow velocity, which is independent of pressure and crack opening, as a function of temperature. As expected, these velocities are much higher than the viscous flow velocities and follow the sonic velocities in lithium vapor closely.

\section{Permissible Lithium Leakage Rate}

Leakage of lithium through the first wall may adversely impact the performance of EVOLVE in two ways. First, by draining the coolant locally from the cracked region, the first wall near the crack may be heated to unacceptably high temperature. Second, lithium atoms evaporating into the plasma chamber will diffuse into the core of the plasma and may lead to unacceptable level of impurity ions in the plasma.

\subsection{Impact on first wall cooling}

Coolant mass flow rate $\left(\frac{\mathrm{dM}}{\mathrm{dt}}\right)$ required for cooling the first wall length containing a crack may be estimated as follows

$$
\frac{\mathrm{dM}}{\mathrm{dt}}=\frac{2 \mathrm{qdc}}{\mathrm{h}}
$$

where $\mathrm{q}=$ surface heat flux, $\mathrm{d}=$ tube diameter, $2 \mathrm{c}=$ crack length, and $\mathrm{h}=$ heat of vaporization of lithium. At a surface heat flux of $2 \mathrm{MW} / \mathrm{m}^{2}$, the minimum coolant mass flow required to cool a $2.5 \mathrm{~cm}$ long segment of the tube is $0.15 \mathrm{~g} / \mathrm{s}$, which is large compared to the conservatively estimated leakage rate of $5 \times 10^{-4} \mathrm{~g} / \mathrm{s}$. Thus, 30 such cracks can be tolerated without impacting the cooling of the first wall locally.

\subsection{Impact on plasma contamination}

Acceptable core impurity level is determined by fuel dilution and radiation; for impurities with low $Z$, fuel dilution is the dominant constraint $[5,6]$. Taking a $20 \%$ power reduction to define the limit and assuming an average core hydrogen density of $1 \times 10^{20} \mathrm{~m}^{-3}$, Rognlien and Rensink [5] have estimated an allowable Li edge density of $3 \times 10^{18} \mathrm{~m}^{-3}$. Using numerical 2D transport simulations, they have calculated the corresponding allowable impurity Li vapor flux to be $2 \times 10^{20}$ atoms $\mathrm{m}^{-2} \mathrm{~s}^{-1}$ for a low-recycling hydrogen case and $3 \times 10^{18}$ atoms $\mathrm{m}^{-2} \mathrm{~s}^{-1}$ for a highrecycling hydrogen case. Both impurity fluxes are large compared to the $10^{17} \mathrm{Li} \mathrm{m}^{-2} \mathrm{~s}^{-1}$ calculated for a single $2.5 \mathrm{~cm}$ long crack. Thus, 30 to 2000 such cracks, depending on hydrogen recycling, can be tolerated without impacting plasma performance. 


\section{Conclusions}

Lithium leakage rate analyses for an EVOLVE first wall with $25 \mathrm{~mm}$ long axial cracks were conducted for two limiting cases - liquid lithium flow and lithium vapor flow. Generally, the mass flow rate is higher for the liquid than the vapor. Of the two, lithium vaporizing at entrance to crack is probably closer to reality. Heat of vaporization of lithium should not limit the leakage rate because it does not have to be supplied by the surface heat flux alone and can be supplied by the coolant and the first wall in the immediate vicinity of the crack.

The lithium vapor flow through a $2.5 \mathrm{~cm}$ long crack should be viscous at temperatures $>$ $1300^{\circ} \mathrm{C}$. Between 1200 and $1300^{\circ} \mathrm{C}$, combined viscous and molecular flow (transition flow) may occur.

Based on this model the maximum Li mass flow rate through a $2.5 \mathrm{~cm}$ long crack at the expected maximum pressure of $0.15 \mathrm{MPa}$ is $5 \times 10^{-4} \mathrm{~g} / \mathrm{s}$. Leakage rate will be even smaller if the initial crack opening is less than $10 \mu \mathrm{m}$ or if tortuosity of a real fatigue crack is included in the analysis. Total leakage rate from 30 such cracks represents $10 \%$ of the $0.15 \mathrm{~g} / \mathrm{s} \mathrm{coolant} \mathrm{flow}$ needed for first wall cooling for a tube segment of $2.5 \mathrm{~cm}$ long. For a first wall area $=500 \mathrm{~m}^{2}$, $5 \times 10^{-4} \mathrm{~g} / \mathrm{s}$ corresponds to $10^{17} \mathrm{Li}$ atoms $\mathrm{m}^{-2} \mathrm{~s}^{-1}$. Since the allowable leakage rate from a plasma contamination viewpoint varies between $3 \times 10^{18}$ and $2 \times 10^{20} \mathrm{Li}$ atoms $\mathrm{m}^{-2} \mathrm{~s}^{-1}, 30$ to 2000 such cracks (i.e., 0.06 to 4 cracks $\mathrm{m}^{-2}$ of first wall area) can be tolerated, depending on the behavior of hydrogen recycling.

\section{References}

1. R.F. Mattas, et al., "EVOLVE - an advanced first wall/blanket system," Fusion Eng. Des. 49-50 (2000) 613-620.

2. R. H. Jones, R. W. Conn, and R. F Schafer, "Effect of First Wall Flaws on Reactor Performance," Nucl. Eng. Des./Fusion 2 (1985) 175-188.

3. A. Zahoor, Ductile Fracture Handbook, E.P.R.I., Palo Alto, 1989.

4. Saul Dushman, Scientific Foundations of Vacuum Technique, Second Edition, J. M. Lafferty, Editor, John Wiley \& Sons, Inc., New York (1962).

5 T. D. Rognlien and M. E. Rensink, "Interactions between Liquid-wall Vapor and Edge Plasmas," Presented at the $14^{\text {th }}$ Int. Conf. Plasma Surface Interactions in Controlled Fusion Devices, Rosenheim, Germany, May 22-26 (2000).

6 R. W. Moir, M. Rensink, and T. D. Rognlien, "Edge Plasma Analysis for Liquid-Wall MFE Concepts," Presented at the $18^{\text {th }}$ IAEA Fusion Energy Conf., Sorrento, Italy, October 4-10 (2000). 



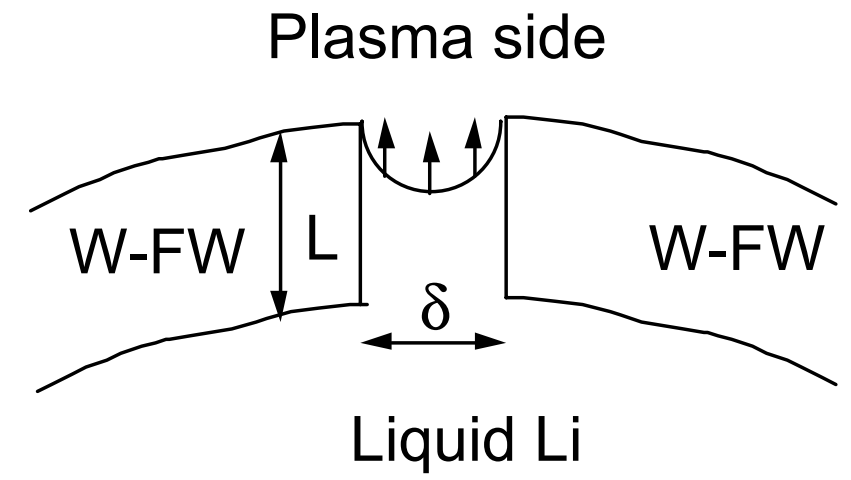

Fig. 1 Liquid lithium meniscus rising through the fatigue crack acts as a capillary pump if liquid lithium wets the fatigue crack flanks. Lithium evaporates into the plasma chamber at the exit plane.

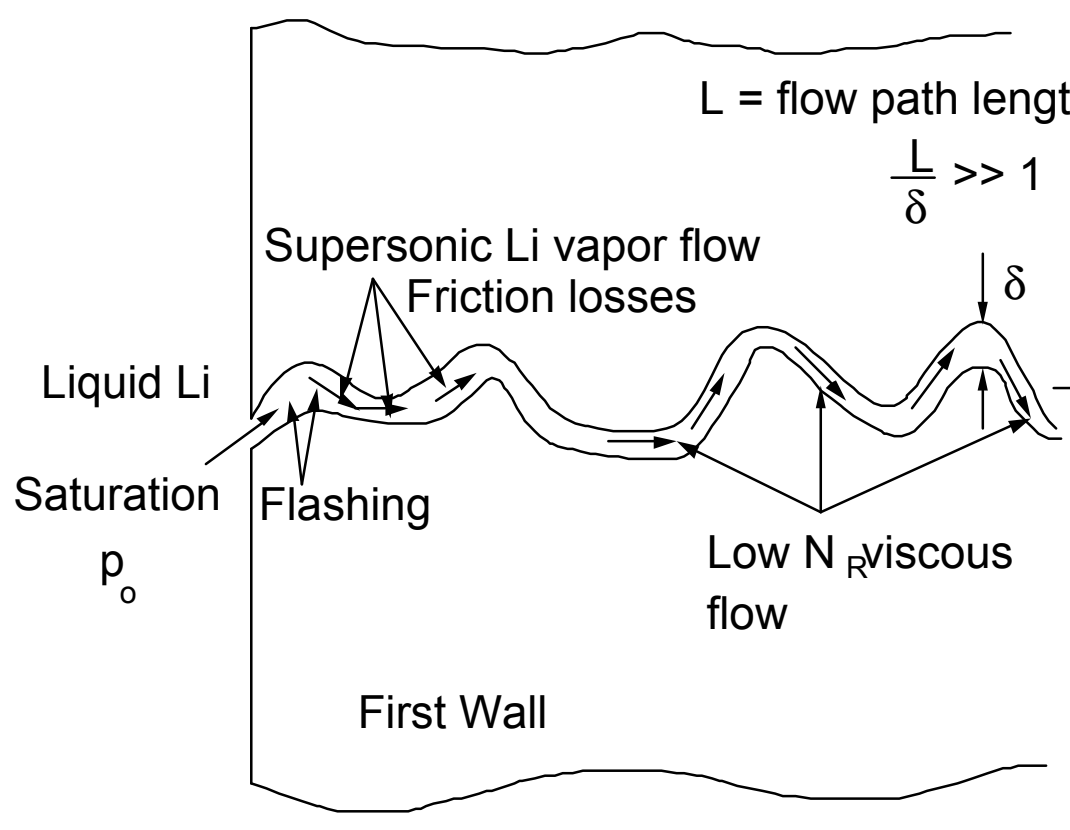

Fig. 2 Schematic of liquid lithium entering a tight and meandering fatigue crack, flashing to high velocity vapor phase close to the inlet, and quickly slowing down to low Reynold's number flow due to dissipations. 


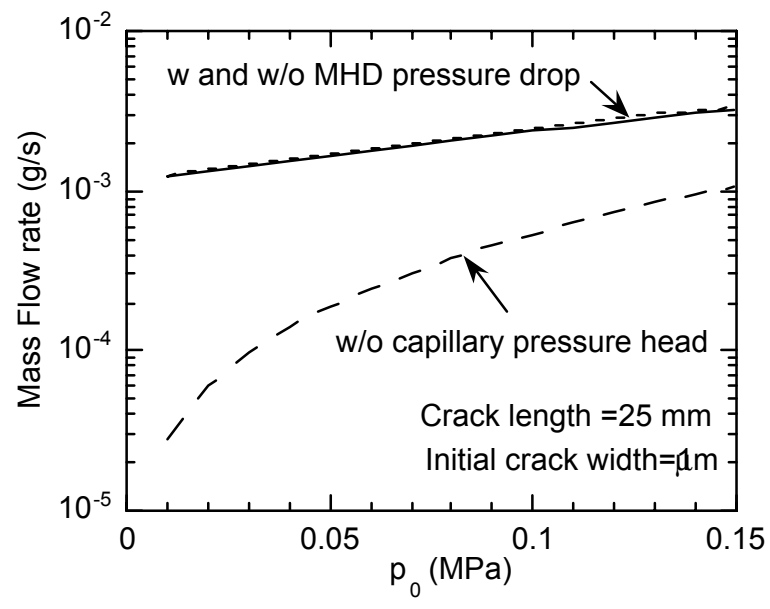

(a)

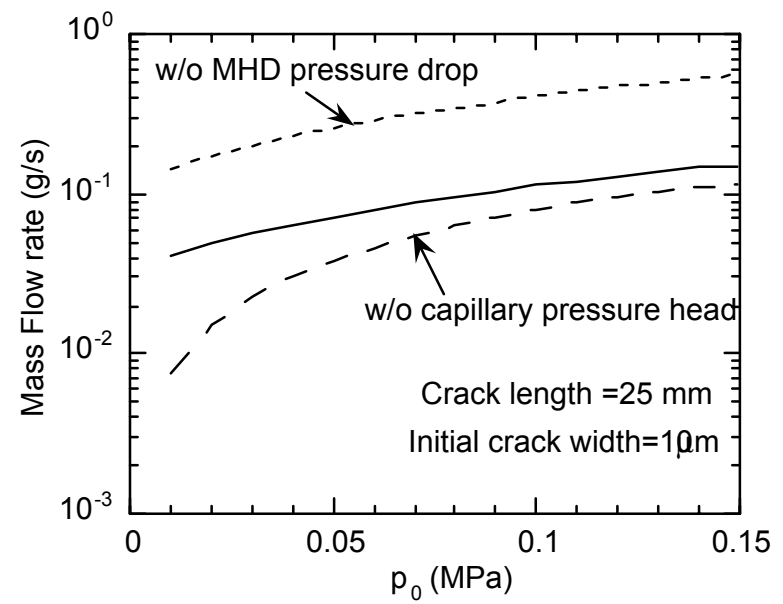

(b)

Fig. 3 Variation of mass flow rate with liquid lithium pressure for a $25 \mathrm{~mm}$ long throughwall crack with initial opening (a) $1 \mu \mathrm{m}$ and (b) $10 \mu \mathrm{m}$. Magnetic field $\mathrm{B}=6$ Tesla.

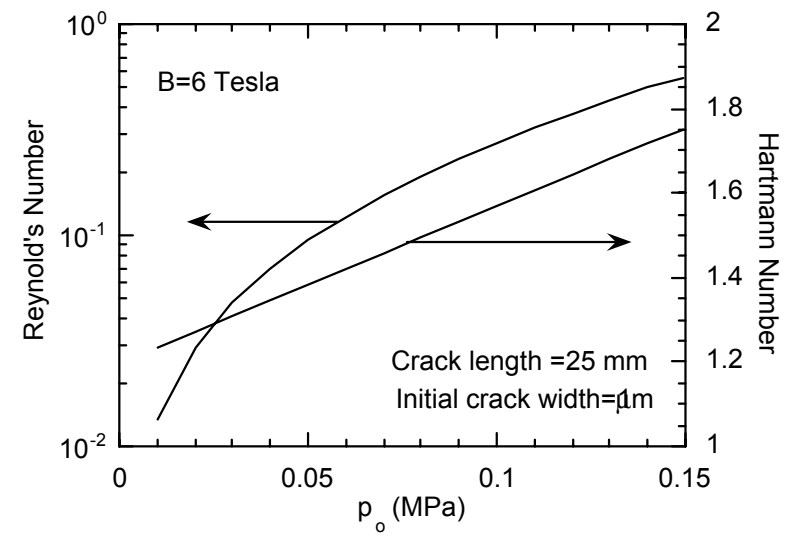

(a)

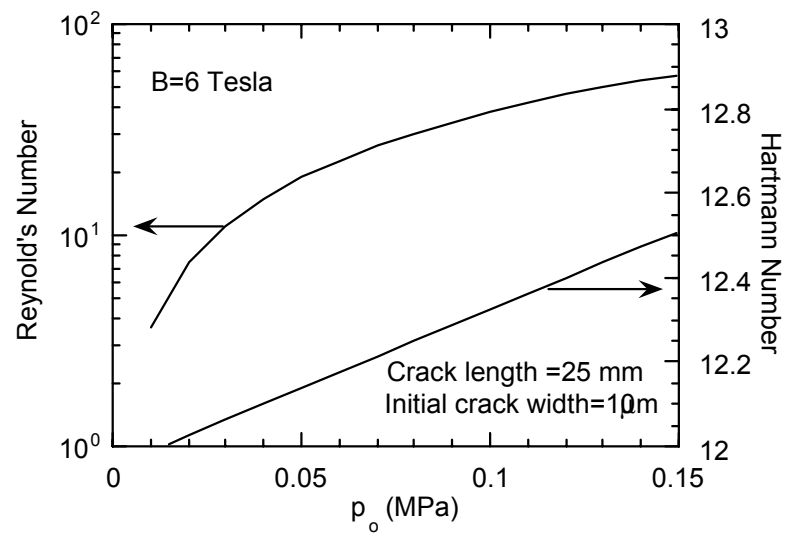

(b)

Fig. 4 Variation of Reynold's number and Hartmann number with liquid lithium pressure for a $25 \mathrm{~mm}$ long throughwall crack with initial opening (a) $1 \mu \mathrm{m}$ and (b) $10 \mu \mathrm{m}$. 


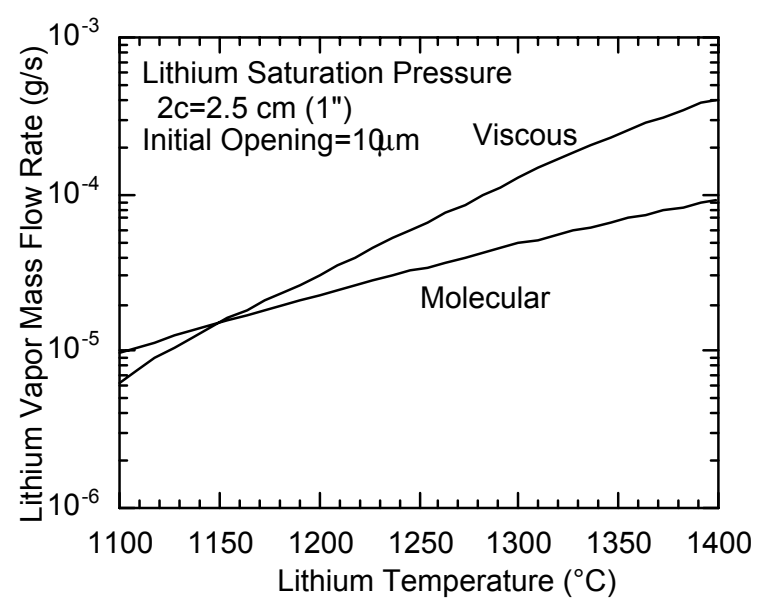

(a)

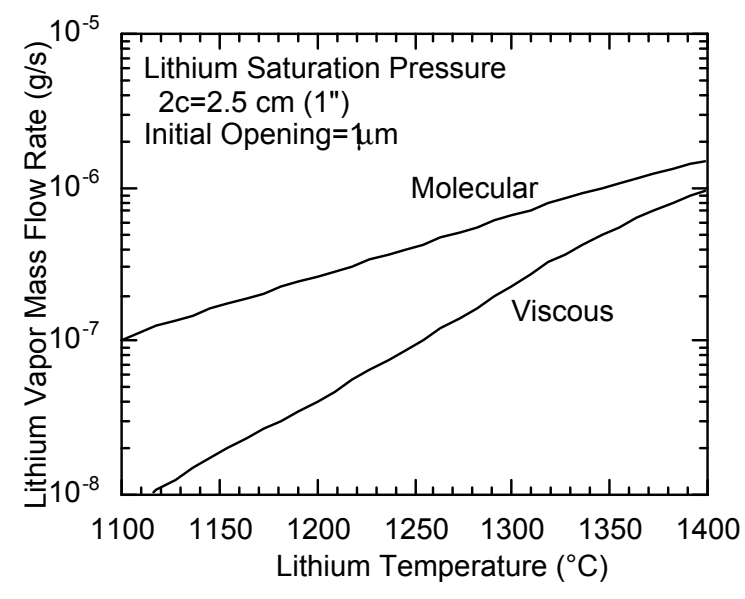

(b)

Fig. 5. Variation of viscous and molecular leakage rates with lithium temperature for a $25 \mathrm{~mm}$ long crack in the EVOLVE first wall for initial crack opening of (a) 10 $\mu \mathrm{m}$ and (b) $1 \mu \mathrm{m}$.

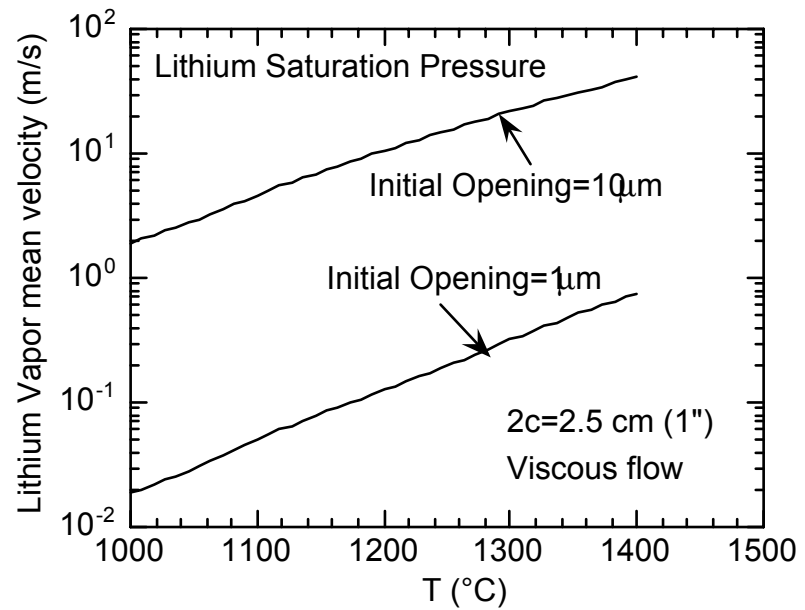

(a)

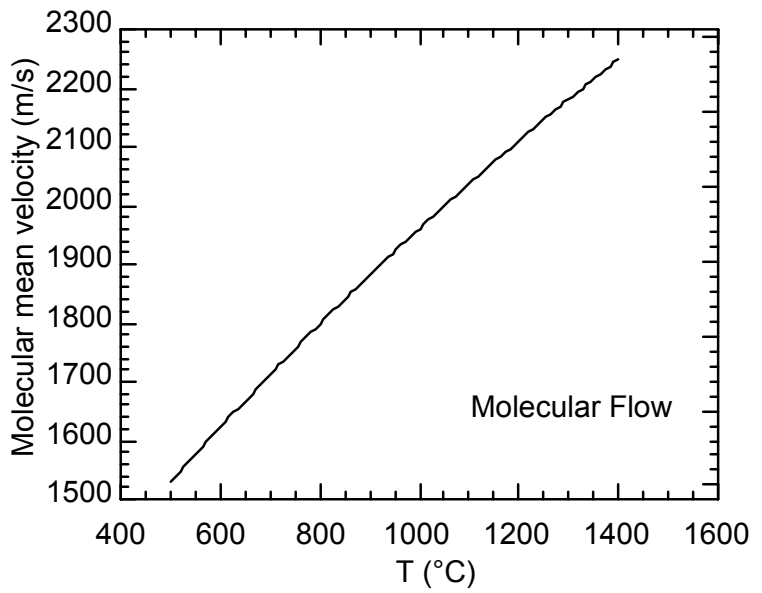

(b)

Fig. 6 Variation of calculated lithium vapor velocity with temperature (a) by incompressible viscous flow theory and (b) molecular flow theory for various initial crack widths of a $25 \mathrm{~mm}$ long crack in the EVOLVE first wall. 